\title{
Impaired meiotic competence in putative primordial germ cells produced from mouse embryonic stem cells
}

\author{
MARIANNA TEDESCO, DONATELLA FARINI and MASSIMO DE FELICI* \\ Department of Public Health and Cell Biology, Section of Histology and Embryology \\ University of Rome "Tor Vergata", Rome, Italy
}

\begin{abstract}
There are still several unanswered questions and problems about the recently claimed possibility of producing functional germ cells in vitro from pluripotent embryonic stem cells (ESCs). In the present paper, we compared by single-cell analysis the capability of putative primordial germ cells (PGCs), produced in vitro from ESCs, and that of endogenous PGCs isolated from embryos, to enter and progress through meiotic prophase I. Using a protocol previously reported to be suitable to produce female germ cells from mouse ESC monolayers, we first identified putative PGCs by analysing the expression pattern of several markers such as SSEA1, APase, OCT4, NANOG, MVH and SCP3 of pre-and post migratory PGCs. Next, after isolation of such cells from culture, we tested their meiotic capability. The evaluation at 2-5 days of culture of the number of cells showing meiotic nuclear SCP3 staining in cytospreads showed that it remained nearly constant in the putative PGCs, whereas it increased markedly in endogenous PGCs. Moreover, we observed that in putative PGCs, the nuclear distribution or expression of SCP3 and other meiotic markers such as DMC1, $\gamma$ H2AX and SCP1 were always highly abnormal in comparison to that observed in endogenous cultured PGCs. We conclude that although the formation of cells showing characteristics of PGCs can occur efficiently from ESCs in vitro, these cells possess impaired capability to enter and progress through meiotic prophase $I$.
\end{abstract}

KEY WORDS: embryonic stem cell, gametogenesis, meiosis, primordial germ cell

From the first report by Hübner et al. (2003) showing that $X Y$ mouse embryonic stem cells (mESCs) are able to produce follicleenclosed growing oocytes, several studies have described the in vitrodifferentiation of female and male germ cells from mouse and human ESCs (hESC) in either the monolayer or the embryoid bodies (EBs) culture method (for reviews see Hua and Sidhu, 2008; Nagano, 2007; Aflatoonian and Moore, 2006). The experiments carried out to produce germ cells from ESCs are based on years of intense investigations on the in vivoand in vitro development of mouse primordial germ cells (PGCs), the oocyte and sperm precursors (for reviews see De Felici, 2009; De Felici et al., 2004; De Felici, 2001). In particular the recent progress in elucidating the process of germ line specification in mammals (Ohinata et al., 2009 and references herein) and the possibility to mimic in vitro events of later PGC development including entering into meiosis (Farini et al., 2005), have given precious information for the derivation and characterization of germ cells produced from ESCs.

In the mouse embryo, PGC development occurs in about 7 days, from around 5.5 days post coitus (dpc), when the first inductive events of the germ cell lineage occur in the epiblast, to $12.5 \mathrm{dpc}$ when sex differentiation of PGCs into meiotic oocytes in the female and G0-arrested prospermatogoni/gonocytes in male

\footnotetext{
Abbreviations used in this paper: APase, alkaline phosphatase; bFGF, basic fibroblast growth factor; BLIMP, B-lymphocyte induced maturation; BMP, bone morphogenetic protein; Daz, deleted in azoospermia; Dazl, deleted in azoospermial-like; DMC, disrupted meiotic cDNA; dpc, days post coitum; EB, embryoid body; EG, embryonic germ; eGFP, enhanced green fluorescent protein; epiSC, epiblast stem cvell; FACS, fluorescence-activated cell sorting; GFP, green fluorescent protein; ePGC, endogenous primordial germ cell; hEG, human embryonic germ; hESC, human embryonic stem cell; KL, kit ligand; IF, immunofluorescence; LIF, leukemia inhibitory factor; MEF, mouse embryonic fibroblast; mESC, mouse embryonic stem cell; MLH, mutL homolog; MVH, mouse VASA homolog; PRDM, PR domain containing; PGC, primordial germ cell; pPGC, putative primordial germ cell; RA, retinoic acid; SMC, structural maintenance of chromosome; STAG, stomalin antigen; SCP, synaptonemal complex protein; SSEA, stage-specific embryonic antigen; SDF, stromal cell-derived factor.
}

\footnotetext{
*Address correspondence to: Massimo De Felici. Dipartimento di Sanità Pubblica e Biologia Cellulare, Università di Roma "Tor Vergata", Via Montpellier, 1, 00173 Roma, Italy. Fax: +39-06-7259-6172. e-mail: defelici@uniroma2.it
} 
occur (for a review, see Western, 2009). Elegant recent studies have shown that mouse PGCs are derived from a few precursors located at the proximal posterior epiblast, which around $6.25 \mathrm{dpc}$ express the transcription factor B-lymphocyte induced maturation protein1 (BLIMP1 also known as PR domain containing 1 (PRDM1)) (Ohinata etal., 2009 and references herein). PGCs are finally specified at the base of the allantois around $7.5 \mathrm{dpc}$ and move into the gonadal ridges between 8.5 and $11.5 \mathrm{dpc}$ (for reviews, see Hayashi et al., 2007; De Felici, 2009). By 12.5 dpc, the ovary and testis become morphologically distinguishable and PGCs initiate sex-specific development. During migration and for a couple of days after gonad colonization, the somatic status of imprinted genes in PGCs is progressively erased (Szabo and Mann, 1995; Szabo et al., 2002; Hajkova et al., 2002; Lee et al., 2002; Kato et al., 1999). Besides the expression of genes and other markers shared from PGCs and ESCs (see below), this epigenetic modification is a valid criterion to distinguish PGCs from ESCs. At $13.5 \mathrm{dpc}$ female PGCs enter meiosis becoming primary oocytes which pass through the meiotic prophase I stages (leptotene/zygotene/pachytene) until around and early after birth become arrested at the diplotene stage. Differently, male PGCs enter mitotic arrest and developed as spermatogonial will be reactivated to initiate spermatogenesis only after birth. Recent studies reported that the decision of meiotic entry or mitotic arrest of post migratory PGCs is regulated by retinoic acid (RA). Male PGCs do not enter meiosis because an enzyme (CYP26b1) expressed in somatic cells in the male gonadal ridge degrades RA. In contrast, the lack of CYP26b1 expression in the embryonic ovary allows PGCs to enter meiosis (for a review, see Bowles and Koopman, 2007). Under various in vivo and in vitro conditions, male PGCs until $12.5 \mathrm{dpc}$ can be, however, induced to enter meiosis likely if exposed to RA at the right time (for a review, see Kocer al., 2009). This indicates that germ cell sex depends on sex-determining signalling from the environment rather than the sex chromosomes. RA is considered the meiotic inducer also in spermatogonia at later postnatal stages (Pellegrini et al., 2008; Anderson et al., 2008). Intriguing, RA can stimulate mitotic proliferation of sex undifferentiated PGCs (Koshimizu et al., 1995; De Felici, 2000) and prevent mitotic arrest of male prospermatogonia in the fetal testis (Trautmann et al., 2008). Moreover, in combination with leukemia inhibitory factor (LIF) and kit ligand $(\mathrm{KL})$, RA favours the formation of embryonic germ (EG) cells from sex undifferentiated PGCs (Koshimizu et al., 1997). Thus indicating that germ cell response to RA is strictly developmental stage dependent.

On the basis of the information summarized above and the analyses of germ cell-specific gene expression dynamics and epigenetic methylation status of imprinted loci to identify PGCs, some recent studies have concluded that bona fide
PGCs can be actually produced both from mouse and human ESCs and that their formation recapitulates many of the crucial developmentally-timed events that occur in the embryo (Wei et al., 2008; West et al., 2010; Kee et al., 2009). The assessment of properly differentiated PGC status requires, however, the demonstration that these cells are able to enter and progress into meiotic prophase I after reaching the premeiotic stage. While the expression of premeioitic markers such as mouse Vasa homolog (MVH) and synaptonemal complex protein 3 (SCP3) or other proteins involved in meiosis (i.e. disrupted meiotic cDNA 1, DMC1, and mutL homolog 1, MLH1) is readily detected in putative PGCs produced form ESCs both at mRNA and protein level, their meiotic capability has been accurately analysed in a few papers only likely for the lack of a suitable method to quantify such process in single PGCs in vitro. Novak et al. (2006) using $X Y$ mouse ESC (mESC) monolayers and a panel of meiosis-specific markers and cytospreads to identify stages of meiotic prophase I found that up to $40 \%$ of the cells within colonies grown onto the culture dish or in suspension considered putative PGCs at 14-16 days of culture expressed the synaptonemal complex protein3 (SCP3). However, they also found that these cells did not express other two synaptonemal complex proteins SCP1, SCP2 and some meiotic proteins, such as stromalin antigen3 (STAG3), Rec8 (REC8) and structural maintenance of chromosome1 (SMC1). Moreover, in cytospreads such cells showed highly abnormal distribution of SCP3. Nicholas et al. (2009) reported that $1-3 \%$ of putative PGCs formed within mouse XX EBs were able to enter into meiosis in culture as evidenced by SCP expression, but showed limited chromosome alignment and meiotic progression. Similar results have been obtained in hESCs. Tilgner et al. (2008) found that SCP3 protein detected in stagespecific embryonic antigen 1 (SSEA1) positive putative PGCs formed within hESC monolayers was concentrated in cytoplasmic foci outside the nuclear envelope. Likewise, in cells positive for SCP3 observed throughout differentiating hEBs, the protein was localized predominantly in the cytoplasm (Clark et al., 2004). But
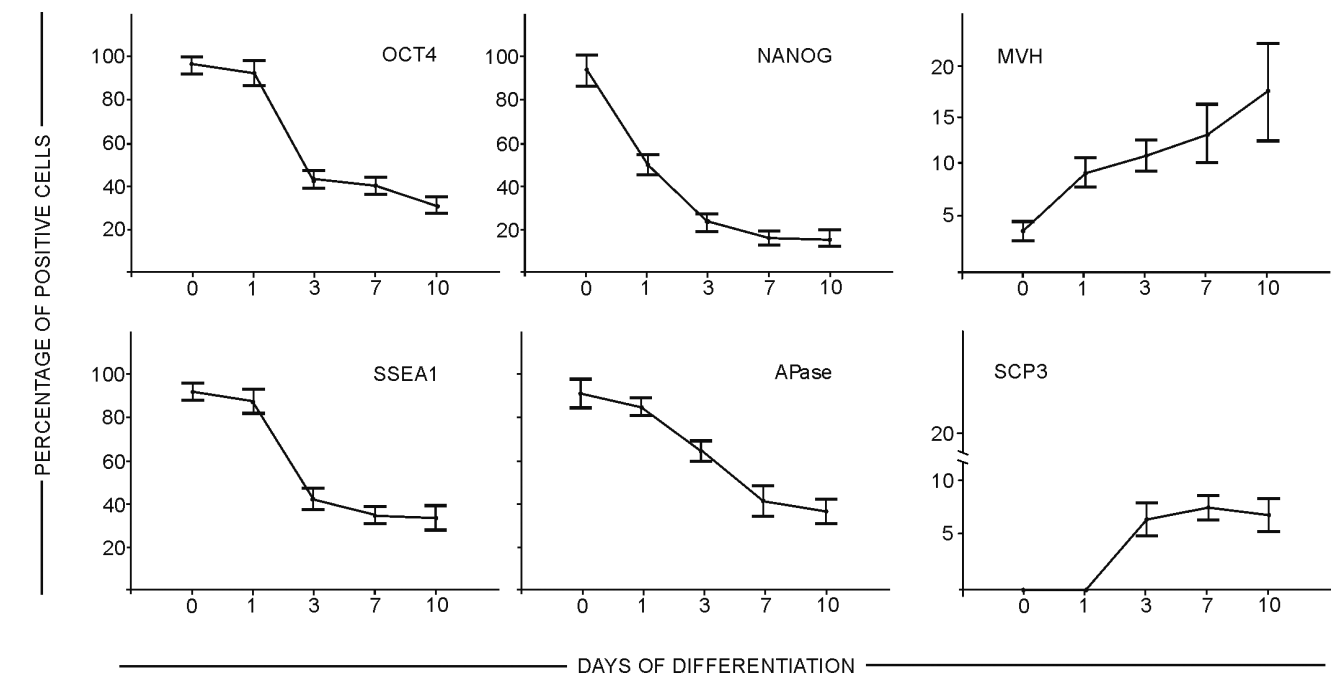

Fig. 1. Expression patterns of various ESC and PGC markers in ESC-D3 cultured for $\mathbf{1 0}$ days. The expression was analyzed using FACS (SSEA1), IF (OCT4, MVH, NANOG, SCP3) or cytochemistry (APase) directly onto the monolayers or on cell samples detached from the monolayer. Similar results were obtained from ESCs cultured for 12 days. 
A
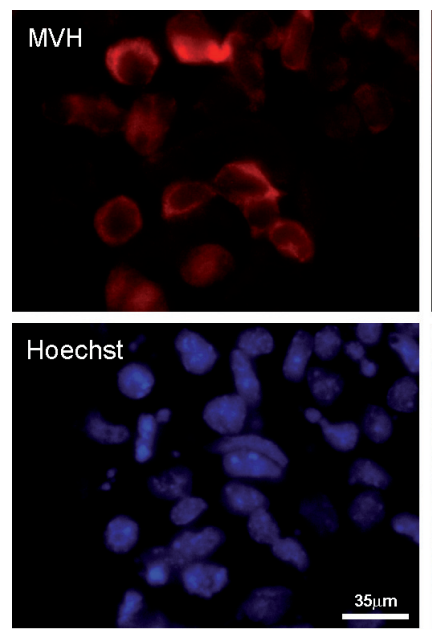

B
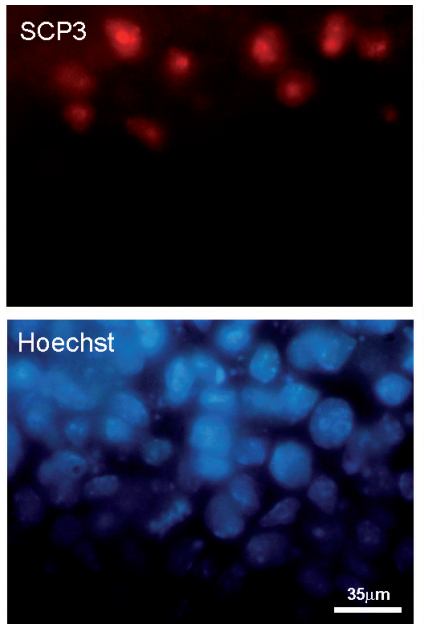

C
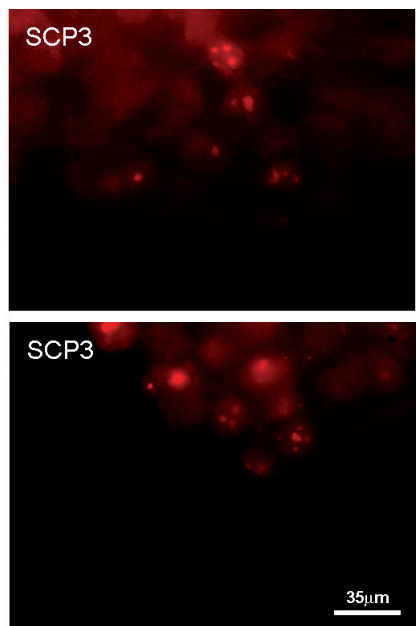

Fig. 2. Representative immunofluorescence for MVH (A) and SCP3 (B,C) performed on ESC monolayers after $\mathbf{1 0}$ days of culture. Nuclear staining with Hoechst is also shown. Similar results were obtained from ESCs cultured for 12 days.

it has also been reported (West et al., 2008) that when hESCs are cultured for 16 days onto mouse embryonic fibroblast (MEF) monolayers in medium supplemented with basic fibroblast growth factor (bFGF), 90\% became positive for MLH1 and SCP3 protein and staining was localized to the nucleus. Finally, in monolayers of XX or XY hESCs cultured for 7 days, Kee et al. (2009) reported the presence of putative PGCs with punctuate (resembling proleptotene/leptotene stages) or elongated (considered zygotene/ pachytene/diplotene stages) SCP3 nuclear staining in the range from 3 to $27 \%$ and $0-10 \%$, respectively, but only after inducing deleted in azoospermia (Daz), deleted in azoospermia-like (Dazl) and/or Boule over expression.

The lack of crucial information about the meiotic capability of the ESC-derived putative PGCs and the recent development of an in vitro culture method in which the majority of the mouse PGCs isolated from the gonadal ridges of 11.5-12.5 dpc embryos enter and progress through meiotic prophase I stages in the absence of somatic cells (Farini et al., 2005), prompted us to precisely evaluate the capability of the putative PGCs produced from mouse ESC monolayers to enter and progress through the stages of meiotic prophase I.

\section{Results}

In a first series of experiments, we sought to reproduce the process of PGC formation from mESCs following the protocol used by Hübner and coll. (2003). To this aim, we used the D3-ESC and analyzed the expression pattern of two ESC and PGC markers, the surface antigen SSEA1 by fluorescence-activated cell

A

A SSEA1 + isolated cells

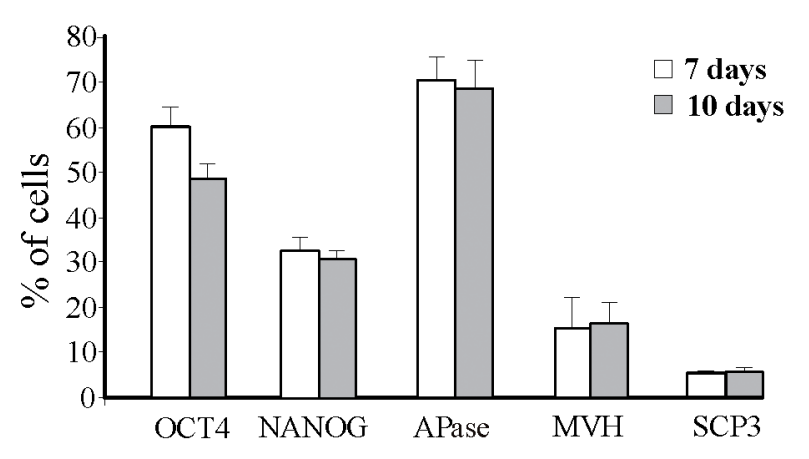

Fig. 3. Characterization of putative PGCs (pPGCs) after 7-10 days of culture. (A) Expression of OCT4, NANOG, APase, MVH and SCP3 protein in SSEA1+ cells immunoisolated from the ESC monolayer by TG1 after 7 and 10 days of culture. The evaluation was performed with IF in cell samples attached to poly-l-lysinecoated slides. (B) A representative FACS analysis of Oct4-GFP ES-OG2+ cells after 10 days of culture for SSEA 1 positivity. Note that the most part of gcOct4-GFP+ cells are also SSEA1+ (Q2). Similar results were obtained from putative PGCs isolated from ESCs cultured for 12 days. sorting (FACS) and the enzyme alkaline phosphatase (APase) by cytochemistry (Donovan and de Miguel, 2003). Such analyses were performed from the beginning of culture up to 12 days under spontaneous differentiation of ESCs as monolayers. In addition, during the same period, we studied by immunofluorescence (IF) the expression of the transcription factors OCT4 and NANOG, also expressed both in ESCs and PGCs (Elliot et al., 2007) and of MVH and SCP3, two proteins specific for pre-and meiotic PGCs (Tanaka et al., 2000; Di Carlo et al., 2000). In line with several other works (Hübner et al., 2003; Wei et al., 2008; Nicholas et al., 2009; West et al., 2009; Haston et al., 2009), we observed that the number of cells positive for SSEA1, APase, OCT4 and NANOG undergo a progressive decrease during the culture time although with different kinetics (Figs. 1-2). While at the beginning of culture $90-100 \%$ of cells were positive for all markers, at the end of the culture period examined (12 days), only about $20 \%$ of the cells expressed these markers. On the contrary, the number of cells expressing MVH increased from less than $5 \%$ to approximately $20 \%$. Cells showing SCP3 appeared around 3 days of culture and from then onward represented about $7 \%$ of the cultured cells. These analyses together with the results reported in previous works reported above allowed considering the SSEA1+ cells after 7-12 days of culture or a subpopulation within them as putative PGCs.

The phenotype of such putative PGCs was further characterized by immunoisolation of SSEA1+ cells from D3-ESC monolayers at 7 and 12 days of culture and carrying out immunofluorescence on single cells for OCT4, APase, NANOG, MVH and SCP3. The results showed that at 7 days of culture the majority of the SSEA $1+$ cells were also APase+ $(70 \% \pm 7)$ and OCT4+ $(60 \% \pm 5)$, while only a subset of these cells were NANOG+ $(33 \% \pm 5)$ and 
$\mathrm{MVH}+(15 \% \pm 10)$; less than $10 \%$ of the SSEA $1+$ cells were stained for SCP3 (Fig. 3A). Similar results were obtained at 12 days of culture (not shown).

Parallel experiments carried out under the same culture conditions using the Oct4-GFP ES-OG2 cells used by Hübner and coll. (2003), showed expression pattern of the gcOct4transgene similar to that of endogenous OCT4 reported above (not shown) and almost complete coexpression of the transgene and SSEA1 marker after 10-12 days of culture (Fig. 3B).

All these results are consistent with the notion that at 7-12 days of culture around $20 \%$ of SSEA1+ putative PGCs are present among cultured ESCs and a significant fraction of them, approximately $10 \%$, express premeiotic $\mathrm{MVH}+\mathrm{SCP} 3+$ proteins. We reasoned that by isolating the SSEA1+ or OCT4+ putative PGCs from the culture at 7-12 days and maintaining them under suitable culture conditions previously used with endogenous PGCs immunoselected with antibodies against SSEA1 from gonads (Farini et al., 2005), we should be able to induce those at earlier stages of differentiation (MVH- and SCP3-) to progress at premeiotic stages and those about to begin meiosis (MVH+ and SCP3+) to enter and progress through the meiotic prophase I stages. In fact, the capability to enter into meiosis in response to RA is normally acquired by PGCs around 12.5-13-5 dpc about 7 days after their specification and is associated to MVH and SCP3 expression (Toyooka et al., 2000; Di Carlo et al., 2000). In vivo, SCP3 expression is first detected as punctuate nuclear staining at meiotic leptotene. Subsequently, SCP3 localizes along the entire length of the sister chromatids as part of the lateral element of the synaptonemal complex (Di Carlo et al., 2000). PGCs at early stages of differentiation can acquire the capability to enter meiosis following a similar timeline outside the gonadal ridges in

A

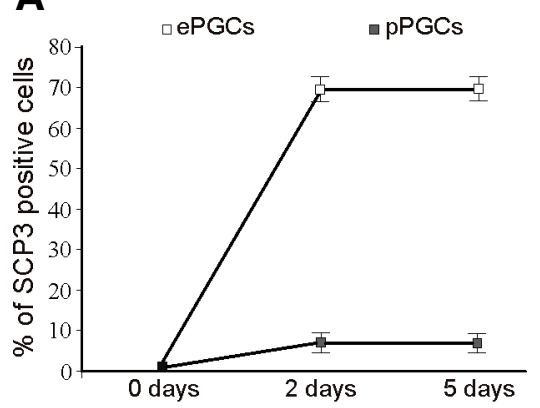

Fig. 4. Capability of putative PGCs (pPGC) and endogenous $12.5 \mathrm{dpc}$ PGCs (ePGCs) to enter and progress through meiotic prophase I. (A) Entering into meiosis of TG-1 immunoselected SSEA1 positive cells ( $p$ PGCs) obtained from 7 day ESC monolayers and PGCs isolated from 12.5 dpc gonads (ePGCs) during 5 days of culture evaluated as percentage of SCP3 positive cells in cytospreads. (B) Cytospreads stained for SCP3. Right panel:

B
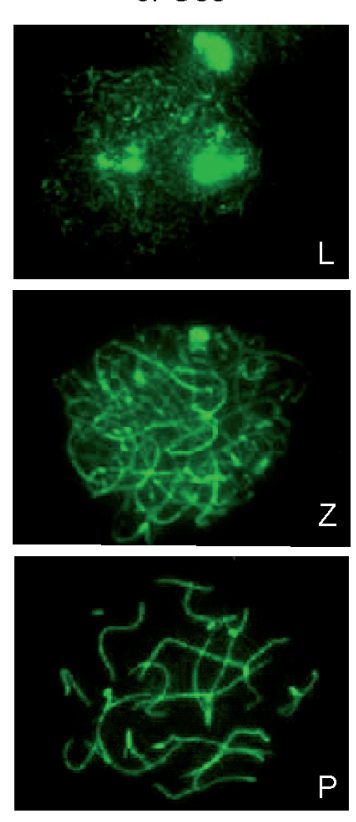

$\mathrm{SCP} 3$ culture (Chuma and Nakatsuji, 2001; McLaren and Southee, 1997).

Evaluation of the percentage of cells showing meiotic nuclear SCP3 staining in cytospreads of putative PGCs and endogenous PGCs immunoselected with antibodies against SSEA1 from the ESC monolayers at 7-12 days or from 12.5 dpc gonads, respectively, at the beginning and after 2-5 days of culture in the Farini's medium (Farini et al., 2005) is reported in Fig. 4A. It appeared that while during this culture period the number of SCP3+ cells in endogenous PGCs increased markedly, it remained nearly constant in putative PGCs. Moreover, the nuclear distribution of SCP3 in putative PGCs was always highly abnormal and not clearly associated with chromosomes as instead observed in control PGCs in the most part of which various apparently morphologically normal prophase I stages were recognizable (Fig. $4 \mathrm{~B})$. Other markers used to determine entering (DMC1 and $\gamma \mathrm{H} 2 \mathrm{AX}$ ) and progression (SCP1) into meiosis also showed abnormal or no expression. In particular, putative PGCs in culture showed only a few foci of DMC1 and small spots of $\mathrm{CH} 2 \mathrm{AX}$ staining instead of the numerous DMC1 foci and the large, cloudlike regions of $\gamma \mathrm{H} 2 \mathrm{AX}$ labelling observed in the nucleus of meiotic PGCs; no SCP1 staining, indicative of the zygotene stage, was detectable in the putative PGGs (Fig. 5).

Putative OCT4-GFP+ PGCs isolated from Oct4-GFP ES-OG2 by FACS also showed the same features of impaired meiotic competence (data not shown).

\section{Discussion}

While it is unquestionable that it is possible to produce in vitro cells with some characteristics of sperm and oocytes both from

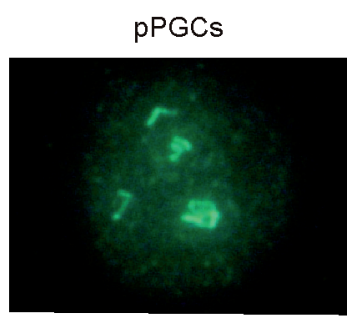
sequence of the events leading to the germ cell development remains elusive. In addition the efficiency of such process is not clear and the functionality of the produced germ cells is often not proven. In fact so far only two papers reported germ cells derived from mESCs able to produce male germ cells at advanced stages of differentiation and to induce apparently normal fertilization and embryo development after injection into oocytes (Nayernia et al., 2006; Geijsen et al., 2003). Since in the embryo gametogenesis begins with the formation of PGCs it is logical to assume that this process should first occur when ESCs differentiate through the germ line. Several recent papers have actually reported convincing evidence that mouse and human ESCs can spontaneously or after stimulation with specific growth factors, namely bone morphogenetic protein 4 (BMP4), give rise to cells showing phenotypic and molecular characteristics of pre-and post-migratory PGCs (see Introduction).

The results obtained in the present 
pPGCs
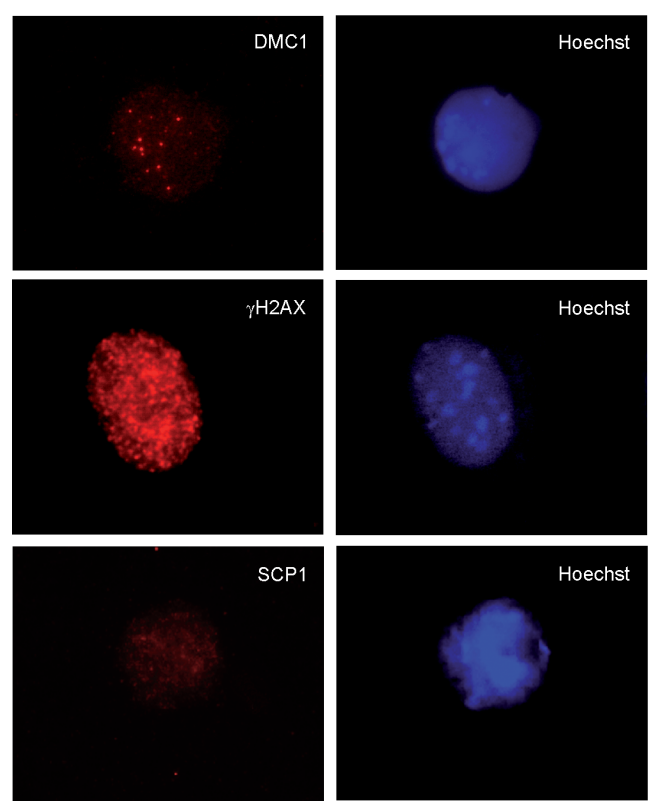

ePGCs
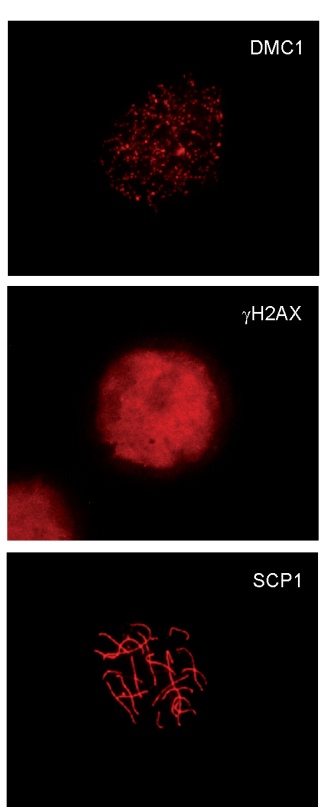
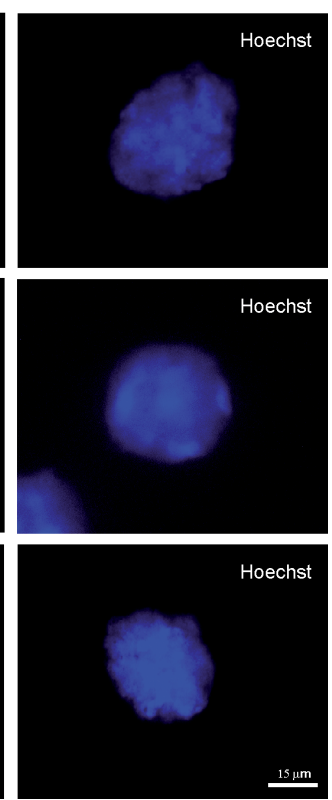

Fig. 5. Cytospread staining for DMC1, cH2AX and SCP1 in putative PGCs (pPGCs) isolated from ESCs after 10-12 days of culture and endogenous PGCs (ePGCs) in culture. Note abnormal DMC1 and CH2AX staining and absence of SCP1 staining in PPGCs in comparison to ePGCs as described in the text.

and the present results we can speculate that the ability of PGCs to respond to the meiotic induction by RA requires the acquisition of "meiotic competences" not properly or rarely achieved after their formation in the ESC culture systems employed so far. It is known, that endogenous PGCs can acquire such capability outside the gonads following a precise timeline in culture covered by the culture periods used in the present work (Chuma and Nakatsji, 2001).This suggests defective or incomplete PGC differentiation from ESCs under a variety of different culture conditions. In line with this notion, micro-array analyses have shown that many "PGC signature" genes (i.e. Dazl, Mvh and developmentalpluripotency-associated protein 2, Dppa2) were not fully up-regulated in putative PGCs obtained from Mvh-LacZ or MvhGFP knock-in mouse ESCs (Mise et al., 2008).

Despite the present results, we

paper are in accord with the reports that putative PGCs can arise from ESC monolayers after relatively short time of culture reflecting timing of PGC formation from the epiblast (Wei et al., 2008; West et al., 2010; Kee et al., 2009). Since the formation of putative PGCs in culture is likely asynchronous it is difficult to properly follow the differentiated status reached by single cells. For this reason, we decided to isolate cells expressing markers of early and pre-meiotic PGCs at 7-12 days and to evaluate their capability to enter and progress through meiotic prophase I stages using cytospreads immunolabeling for meiotic markers including the synaptonemal complex proteins SCP1 and SCP3 and the recombination proteins DMC1 and $\gamma \mathrm{H} 2 \mathrm{AX}$. The results showed that, at this time, putative PGCs originated from cultured ESCs are basically meiotic incompetent or showed severe meiotic anomalies. So far the meiotic competence of ESC-derived putative PGCs has been little investigated likely for the lack of a suitable assay to analyse and quantify such event in comparison to endogenous PGCs isolated from the embryo. Here we report that when exposed to a cocktail of growth factors including RA, considered to be the physiological inducer of meiosis in PGCs (for a review, see Bowles and Koopman, 2007), putative PGCs spontaneously produced from ESC monolayers have a much lower capability to enter and progress through meiotic prophase I in vitro in comparison to endogenous PGCs. As reported in the Introduction, human putative PGCs formed in ESC monolayers appear to possess a quite variable meiotic capability ranging from about 3 to $20 \%$ but only after over expression of specific genes (Kee et al., 2009). Moreover, we observed in line with previous works carried out in mouse (Novak et al., 2006; Nicholas et al., 2009) and in human ESCs (Clark et al., 2004; Tilgner et al., 2008), a severe impairment in the capability of such putative PGCs to organize a normal meiotic synaptonemal complex. From these cannot exclude that some cells able to enter meiosis were undetected in our assay or will enter meiosis after longer period in culture or if transferred into a favourable environment. In this regard, strong evidence exists that both mouse and human ESCs can give rise to haploid germ cells resembling spermatocyte/ spermatides or even tailed sperm after relatively long culture time (mouse:Toyooka et al., 2003; Geijsen et al., 2003; Najernia et al., 2004 and 2006; Kirkis et al., 2007; Yu et al., 2009; human: Tilgner et al., 2008; Aflatoonian et al., 2009) Thus suggesting that PGCs produced in ESC culture more frequently differentiate towards male rather female germ line characterized by entering into meiosis only at later postnatal developmental stages. Considering only the more convincing results obtained in the mouse, it appears that efficient differentiation of the ESC-derived germ cells through advanced spermatogenic stages requires transplantation into a favorable testicular environment and does not necessitate stage-matched testicular cells. Interestingly, these characteristics also belong to endogenous PGCs which from as early $8.5 \mathrm{dpc}$ have been reported to colonize the testis of infertile newborn mice and enter spermatogenesis (Chuma et al., 2005).

How our observations may conciliate with the studies reporting the formation of oocyte-like cells in the ESC culture? None of these studies clearly documented the presence of meiotic PGCs preceding the appearance of the oocyte-like cells, nor the functionality of these latter. Moreover, the frequency of formation of the oocyte-like cells was very low or not reported. In fact, although oocyte-like cells enclosed within follicle-like structures were observed by Hübner and coll. (2003) after about 1 month of culture of D3-ESCs, the frequency, the meiotic stage and functional data concerning these cells were not provided. Lacham-Kaplan et al. (2006) reported that EBs cultured in the conditioned medium derived from newborn mouse testis germ cells developed ovarian 
structures containing unspecified number of putative oocytes; the oocyte-like cells were surrounded by one to two layers of flattened cells and did not have a visible zona pellucida; oocyte-specific markers, such as Fig $\alpha$ and Zp3, were expressed by the ovarian structures. The same two papers cited above showing the formation of tailed sperm reported the presence of oocytes-like cells in their mouse ESC culture systems (Kirkis et al., 2007 and Yu et al., 2009). Outgrowth of 4 day EB cells containing putative PGCs onto newborn ovarian granulosa cells formed a few oocyte-like cells $25 \mu$ in size after 10 days of culture (Qing et al., 2007). These cells expressed some oocyte specific genes such as Fig $\alpha$, Gdf9 and Zp1-3, but showed abnormal SCP3 staining in the cytoplasm. In ESCs stably transfected with the promoter region of the mouse Gdf9 coupled to enhanced green fluorescent protein (eGFP) and cultured on feeder cell layers, large eGFP-positive cells, surrounded by a structure resembling a zona pellucida appeared transiently and very rapidly on the first days of culture. However, in EB cultures, eGFP-positive cells appeared transiently and then reappeared in regional clusters after a relatively long culture of 30-45 days (Salvador et al., 2008). Finally, putative PGCs obtained from 21 day EBs reaggregated with newborn ovarian tissues and transplanted under the kidney capsule of recipient mice give rise to oocytes enclosed in primary follicle at very low frequency $(0.023 \%)$ (Nicholas et al., 2009). In humans, as far as we know, only two papers reported the occasional formation of oocytes-like cells from ESCs (Chen et al., 2006; Aflatoonian et al., 2009).

The lack of evidence of proper beginning and progression through meiotic prophase I by putative PGCs and the available information about the characteristics of the oocyte-like cells produced in vitro raise doubts that continuous female gametogenesis can be correctly reproduced in the present ESC culture systems. In fact, even PGCs isolated from the embryo as early as $10.5 \mathrm{dpc}$ although able to enter and progress through meiotic prophase I outside the gonad are unable to reach the growing oocyte stage (Chuma and Nakatsuji, 2001; Farini et al., 2005). This can be achieved by isolated fetal oocytes providing availability of the growth factor kit ligand $(\mathrm{KL})$ and subsequently of follicular cell support (Klinger and De Felici, 2002). Moreover, several studies indicate that synchronized interactions between oocytes and ovarian somatic cells are important to ensure normal ovogenesis (Qing et al., 2008 and references therein).

In conclusion, we postulate that the formation of oocyte-like cells reported in ES culture may bypass the normal entering and progression of the putative PGCs through meiotic prophase I and is occasionally induced only when a contemporary differentiation of follicular-like cells from the surrounding ESCs occurs.

Finally, two recent papers reported that putative PGCs can be formed in vitro with high efficiency from epiblast and epiblast stem cells (EpiSCs), the cell type from which endogenous PGCs originate (see Introduction) (Ohinata et al., 2009; Hayashi and Surani, 2009). Such PGCs appear to posses gene expression and epigenetic signature very close to endogenous migratory PGCs. While the meiotic competence of the epiblastderived cells were not investigated, EpiSC-derived PGCs after 7 days of culture form undetermined number of SCP3+ cells when co-cultured with $12.5 \mathrm{dpc}$ ovarian cells and oocyte-like after about 40 days of culture at low frequency (around $0.02 \%$ ).
All together these results demonstrate a robust spontaneous or inducible formation of bona fide PGCs from ESCs but a relatively low or defective formation of germ cells in the culture dishes at later stages of differentiation mainly in the female germ line. Here we show that such defect may originate from abnormal or incomplete in vitro PGC specification relatively to the acquisition of the meiotic competence at the time proper of the female germ line. Recent papers indicate that epigenetic status (Wang and Tilly, 2010) and elevated expression of certain genes (i.e. Daz) (Kee et al., 2009; Lin et al., 2008; Linher et al., 2009) is crucial for the meiotic commitment of PGCs. Such processes could be altered in putative PGCs. One of the major challenges for future studies will be the identification of the molecular basis of the PGC meiotic competence and the compounds and/or conditions able to induce such competence in PGCs produced from ESCs or epiblast cells in vitro.

\section{Materials and Methods}

\section{ESC culture}

The XY ESC-D3 (ATCC) and the Oct4-GFP ES-OG2 (a kind gift of Prof. H. Shöler, Max Plank Institute, Monster) lines were maintained on mitomycin C-treated MEFs in $0.1 \%$ gelatin-coated tissue culture plates in Dulbecco's modified Eagle's medium (D-MEM) containing $4.5 \mathrm{~g} / \mathrm{l}$ glucose, $100 \mathrm{mM}$ non-essential amino acids, $0.1 \mathrm{mM}$ 2-mercaptoethanol, 2 $\mathrm{mM}$ L-glutamine, $0.25 \mathrm{mM}$ pyruvate, $N$-acetyl-I-cysteine, $75 \mathrm{mg} / \mathrm{L}$ penicillin-G, $50 \mathrm{mg} / \mathrm{L}$ streptomycin (Sigma) supplemented with $15 \%$ fetal bovine serum (Invitrogen) and 1,000 U/mI LIF (ESGRO). Cultures are trypsinized and expanded at a ratio of 1:7 on fresh feeder cells every $48 \mathrm{~h}$, when the colony size reaches approximately 80 to $100 \mu \mathrm{m}$ in diameter.

\section{ESC differentiation}

In order to induce germ cells differentiation of ESCs the protocol described in Hübner et al. (2003) was employed. Briefly the ESCs were grown in medium without LIF and MEFs. The ability of MEFs to reattach faster to a tissue culture plate than ESCs was used for MEF removal. After two round of preplating, the cell suspension contains about $98 \%$ ES cells and only about $2 \%$ MEFs. The ES cells were plated at a density of 1 to $2.5 \times 10^{4} \mathrm{cells} / \mathrm{cm}^{2}$ in gelatinized $6 \mathrm{~cm}$ tissue culture plates in ESC medium without LIF. The medium was replaced on day 3 , if the cultures were confluent. Over the next few days the cell layer overgrows, and substantial cell death took place. The medium was then changed every day and care was be taken to remove as many dead cells and debris as possible.

\section{Isolation and culture of putative PGCs}

Putative-PGCs (pPGCs) obtained in culture were isolated at different days of differentiation following MiniMACS immunomagnetic method (De Felici and Pesce, 1995). Briefly, the cells were resuspended in D-MEM and TG-1 antibody, which recognize SSEA1 epitope, (1:300, generously provided by $\mathrm{P}$. Donovan, University of California, USA); incubation was carried out with continuous agitation at $4^{\circ} \mathrm{C}$. After $45 \mathrm{~min}$, super paramagnetic micro beads suspension conjugated with monoclonal mouse IgM antibody (Miltenyi Biotech) was added. Incubation was carried out for 15 min at $4^{\circ} \mathrm{C}$ with continuous agitation as described above. Cells were than pipetted on top of an AS Column (Miltenyi Biotech) and placed in a MiniMACS separation unit (Miltenyi Biotech). The column was washed 3 times with D-MEM in the magnetic field and the effluent was collected as SSEA1 negative cells. To elute cells retained by the column (SSEA1labeled pPGCs), this was removed from the separation unit, placed on a Eppendorf tube, and flushed out with $1 \mathrm{ml}$ of D-MEM using the plug supplied with the column. Isolated pPGCs were seeded onto a Transwell Falcon cell culture polyethylene terephtalate (PET) membrane filter (Falcon) inserted into a 24-well plate tissue culture dish in a total of $0.9 \mathrm{ml}$ 
$(0.2 \mathrm{ml}$ and $0.7 \mathrm{ml}$ above and below the membrane, respectively) of high glucose D-MEM (Gibco), containing non-essential amino acids, $0.1 \mathrm{mM}$ 2-mercaptoethanol, $2 \mathrm{mM}$ glutamine, $0.25 \mathrm{mM}$ pyruvate, $75 \mathrm{mg} / \mathrm{L}$ penicillin-G, $50 \mathrm{mg} / \mathrm{L}$ streptomycin (Sigma), 15\% fetal calf serum (Gibco), recombinant mouse $\mathrm{KL}$ or stem cell factor (SCF), human bFGF, mouse stromal cell-derived factor 1 (SDF1) and human BMP4 (R\&D System) and $\mathrm{N}$-acetyl-I-cysteine, forskolin and RA (Sigma) (Farini's medium). Growth factors and compounds were added at the time of seeding at the concentration reported in Farini et al. (2005) and changed every day of culture ( 2 or 5 days). Cultures were carried out in a humidified incubator at $37^{\circ} \mathrm{C}$ and $5 \% \mathrm{CO}_{2}$ in air.

\section{Flow cytometry}

Culture plates of differentiating ES-D3 and Oct4-GFP ES-OG2 cells were EDTA-trypsinized 5 min at $37^{\circ} \mathrm{C}$, washed and resuspended in PBS with $0.4 \%$ bovine serum albumin (PBS-BSA). After filtration through a $40 \mu$ cell strainer to remove aggregates, single cell suspensions were incubated for $30 \mathrm{~min}$ on ice in PBS-BSA containing monoclonal antibody against the surface protein SSEA1 conjugated with allophycocyanin (APC) or with an APC-isotype control and then rinsed twice in PBS-BSA. FACS analyses or GFP+ cell sorting were performed using Becton Dickinson FACScalibur and FACScan flow cytometers (Becton Dickinson).

\section{Immuno- and APase staining}

IF was performed on fixed adherent cells or trypsinized single cells detached from the cell monolayers and left to adhere to poly-I-lysinecoated slides before fixation. All samples were fixed with $4 \%$ paraformaldehyde in PBS for 10 minutes at room temperature and then permeabilized for 10 minutes in PBS/0.1\% Triton X-100. After 1 hour in $\mathrm{PBS} / 5 \% \mathrm{BSA}$, the cells were incubated overnight at $4^{\circ} \mathrm{C}$ with the primary antibody to OCT4 (1:300, mouse monoclonal IgGs, SantaCruz), NANOG (1:200, rabbit polyclonal IgGs, SantaCruz) MVH (1:300, rabbit polyclonal IgGs, AbCam), DMC1 (1:200, rabbit polyclonal IgGs, Santa Cruz), $\gamma \mathrm{H} 2 \mathrm{AX}$ (1:104, mouse monoclonal IgG1s,Upstate), SCP1 (1:100, goat polyclonal IgGs, Santa Cruz) or SCP3 (1:100, rabbit polyclonal IgGs, SantaCruz). The next day cells were rinsed three times in PBS and incubated with the appropriate TRITC or FITC conjugated secondary antibodies (1:500 in PBS, AlexaFluor, Molecular Probes) for $45 \mathrm{~min}$ in the dark. For nuclear staining, fixed cells were incubated in PBS for 10 min with Hoechst 33349 dye $(1 \mu \mathrm{g} / \mathrm{ml})$. Cells with only secondary antibodies staining were negative controls. APase staining was performed by cytochemistry as reported in Farini et al. (2005).

The meiotic prophase I stages were determined by characteristics patterns of SCP3 immunolabeling in cytospreads as described in Farini et al. (2005).

\section{Statistical analysis}

All experiments were replicates at least three times. The means were tested for homogeneity of variance, and analyzed by ANOVA. The level of significance was set at $P<0.05$ and $P<0.01$.

\section{Acknowledgements}

We are in debt with Prof. H. R. Schöler and Dr D. Sabour of the MaxPlanck-Institute for Molecular Biomedicine, Münster, for the gift of the Oct4-GFP ES-OG2 cell line and their kind advice and assistance in carrying out part of the experiments. We thank DrM. Stehling for FACS analyses; Dr M. Barchi and C. Antinozzi for generously providing the SCP1 and DMC1 antibodies; Dr F.G. Klinger for help in cytospread preparations. This work was supported by grants from MIUR PRIN 2008 and $A S / 1 / 065 / 08 / 0$

\section{References}

AFLATOONIAN, B., and MOORE, H. (2006). Germ cells from mouse and human embryonic stem cells. Reproduction 132: 699-707.

AFLATOONIAN B., RUBAN L., JONES M., AFLATOONIAN R., FAZELI A. and MOORE H.D. (2009). In vitro post-meiotic germ cell development from human embryonic stem cells. Hum Reprod 24: 3150-3159.

ANDERSON, E.L., BALTUS, A.E., ROEPERS-GAJADIEN, H.L., HASSOLD, T.J., DE ROOIJ, D.G., VAN PELT, A.M. and PAGE, D.C. (2008). Stra8 and its inducer, retinoic acid, regulate meiotic initiation in both spermatogenesis and oogenesis in mice. Proc Natl Acad Sci USA 105: 14976-14980.

BOWLES, J. and KOOPMAN, P. (2007). Retinoic acid, meiosis and germ cell fate in mammals. Development 134: 3401-3411.

CHEN, H.F., KUO, H.C., C.-L.CHIEN, C.L., SHUIN, C.T., YAO, Y.L., IP, P.L., CHUANG, C.Y., WANG, C.C., YANG, Y.S. and HO, H.N. (2007). Derivation, characterization and differentiation of human embryonic stem cells: comparing serum-containing versus serum-free media and evidence of germ cell differentiation. Hum Repr 22: 567-577.

CHUMA, S. and NAKATSUJI, N. (2001). Autonomous transition into meiosis of mouse fetal germ cells in vitro and its inhibition by gp130-mediated signaling. Dev Bio/229: 468-479.

CHUMA, S., KANATSU-SHINOARA, M., INOUE, K., OGONUKI, N., MIKI, I., TOYOKUNI. M.K., HOSOKAWA, M., NAKATSUJI, N., OGURA, A. And SHINOARA, T. (2005). Spermatogenesis from epiblast and primordial germ cells following transplantation into postnatal mouse testis. Development 132 117-122.

CLARK, A. T., BODNAR, M. S, FOX, M., RODRIGUEZ, M.T., ABEYETA, M.J., FIRPO, M. T. and PERA, R. A. R. (2004). Spontaneous differentiation of germ cells from human embryonic stem cells in vitro. Hum Mol Genet 13: 727-739.

DE FELICI, M. (2000). Regulation of primordial germ cell development in the mouse. Int J Dev Bio/44: 575-580.

DE FELICI, M. (2001). Twenty years of research on primordial germ cells. Int J Dev Bio/45: 519-22.

DE FELICI, M. (2009). Primordial germ cell biology at the beginning of the $X X$ Century. Int J Dev Bio/53: 891-894.

DE FELICI, M., SCALDAFERRI, M.L., LOBASCIO, M., IONA, S., NAZZICONE, V., KLINGER, F.G., and FARINI, D. (2004). Experimental approaches to the study of primordial germ cell linear and proliferation. Hum Reprod 10: 197-206.

DE FELICI, M. and PESCE, M. (1995). Purification of muose primordial germ cells by MiniMACS magnetic separation system. Dev Bio/170: 722-727.

DI CARLO, A., TRAVIA, G. and DE FELICI, M. (2000). The meiotic specific synaptonemal complex protein SCP3 is expressed by female and male primordial germ cells of the mouse embryo. Int J Dev Bio/44: 241-244.

DONOVAN, P.J. and DE MIGUEL, P. (2003). Turning germ cells into stem cells Curr Opin Genet Dev 13: 463-471.

ELLIOTT, A., DE MIGUEL, P, REBEL, V. and DONOVAN PJ. (2007). Identifying genes differentially expressed between PGCs and ES cells reveals a role for CREB-binding protein in germ cell survival. Dev Bio/311: 347-358.

FARINI, D., SCALDAFERRI, M.L., IONA, S., LA SALA, G. and DE FELICI M. (2005) Growth factors sustain primordial germ cell survival, proliferation and entering into meiosis in the absence of somatic cells. Dev Bio/285: 49-56.

GEIJSEN, N., HOROSCHAK, M., KIM, K., GRIBNAU, J., EGGAN, K. and DALEY, G.Q. (2004). Derivation of embryonic germ cells and male gametes from embryonic stem cells. Nature 427: 148-154.

HAJKOVA, P., ERHARDT, S., LANE, N., HAAF, T., EL MAARRI, O., REIK, W. WALTER, J. and SURANI, M.A. (2002). Epigenetic reprogramming in mouse primordial germ cells. Mech Dev117: 15-23.

HASTON, K.M., TUNG, J.Y. and PERA, R.A.R. (2009). Dazl functions in maintenance of pluripotency and genetic and epigenetic progress of differentiation in mouse primordial germ cells in vivo and in vitro. PLoS One 4: 1-15.

HAYASHI, K. and SURANI, M.A. (2009). Self-renewing epiblast stem cells exhibit continual delineation of germ cells with epigenetic reprogramming in vitro. Development 136: 3549-56.

HAYASHI, K., DE SOUSA LOPES, S.M. and SURANI, M.A. (2007). Germ cell specification in mice. Science 316: 394-396.

HUA, J. and SIDHU, K. (2008). Recent advances in the derivation of germ cells from the embryonic stem cells. Stem Cell Dev 17: 399-411. 
HUBNER, K., FUHRMANN, G., CHRISTENSON, L.K., KEHLER, J., REINBOLD, R., DE LA FUENTE, R., WOOD, J., STRAUSS, J.F. III, BOIANI, M. and SCHOLER, H.R. (2003). Derivation of oocytes from mouse embryonic stem cells. Science 300: 1251-1256.

KATO, Y., RIDEOUT, W.M., III, HILTON, K., BARTON, S.C., TSUNODA, Y. and SURANI, M.A. (1999). Developmental potential of mouse primordial germ cells. Development 126: 1823-1832.

KERKIS, A., FONSECA, S.A.S., SERAFIM, R.C, LAVAGNOLLI, T.M.C., ABDELMASSIH, S., ABDELMASSIH R. and KERKIS, I. (2007). In vitro Differentiation of Male Mouse Embryonic Stem Cells into Both Presumptive Sperm Cells and Oocytes. Cloning Stem Cells 9: 535-548.

KEE, K., ANGELES, V.T., FLORES, M., NGUYEN, H.N. and PERA, R.A. (2009). Human DAZL, DAZ and BOULE genes modulate primordial germ-cell and haploid gamete formation. Nature 462: 222-225.

KLINGER, F.G. and DE FELICI, M. (2002). In vitrodevelopment of growing oocytes from fetal oocytes: stage-specific regulation by stem cell factor and granulose cells. Dev Bio/244: 85-95.

KOCER, A., REICHMANN, J., BEST, D. and ADAMS, I.R. (2009). Germ cell sex determination in mammals. Mol Hum Repr 15:205-213.

KOSHIMIZU, U., WATANABE, M. and NAKATSUJI, N. (1995). Retinoic acid is a potent growth activator of mouse primordial germ cells in vitro. Dev Biol 168:683-685.

KOSHIMIZU, U., TAGA, T., WATANABE, M., SAITO, M., SHIRAYOSHI, Y., KISHIMITO, T. and NAKATSUJI N. (1997). Functional requirement of gp-130 mediated signaling for growth and survival of mouse primordial germ cells in vitro and derivation of embryonic germ (EG) cells. Development 122: 12351242.

LACHAM-KAPLAN, O., CHY, H. and TROUNSON, A. (2006). Testicular cell conditioned medium supports differentiation of embryonic stem cells into ovarian structures containing oocytes. Stem Cells 24: 266-273.

LEE, J., INOUE, K., ONO, R., OGONUKI, N., KOHDA, T., KANEKO-ISHINO, T., OGURA, A. and ISHINO, F. (2002). Erasing genomic imprinting memory in mouse clone embryos produced from day 11.5 primordial germ cells. Development 129: 1807-1817.

LINN, Y., GILL, M.E., KOUBOVA, J. and PAGE, D.C. (2008). Germ cell-intrinsic and extrinsic factors govern meiotic initiation in mouse embryos. Science322: 16841687.

LINHER, K., DYCE, P. and LI, J. (2009). Primordial germ cell-like cells differentiated in vitro from skin-derived stem cells. PLOS ONE 4: 1-10.

Mc LAREN A. and SOUTHEE D. (1997). Entry of mouse embryonic germ cells into meiosis. Dev Biol187: 107-113.

MISE, N., FUCHIKAMI, T., SUGIMOTO, M., KOBAYAKAWA, S., IKE, F., OGAWA, T., TADA, T., KANAYA, S., NOCE, T. and ABE, K. (2008). Differences and similarities in the developmental status of embryo-derived stem cells and primordial germ cells revealed by global expression profiling. Genes Cel/s 13: 863-877.

NAGANO, M.C. (2007). In vitro gamete derivation from pluripotent stem cells: Progress and perspective. Biol Repr 76: 546-551.

NAYERNIA, K., LI, M., JAROSZYNSKI, L., KHUSAINOV, R., WULF, G., SCHWANDT, I., KORABIOWSKA, M., MICHELMANN, H.W., MEINHARDT, A. and ENGEL, W. (2004). Stem cell based therapeutical approach of male infertility by teratocarcinoma derived germ cells. Hum Mol Gen 14: 1451-1460.

NAYERNIA, K., NOLTE, J., MICHELMANN, H.W., LEE, J.H., RATHSACK, K., DRUSENHEIMERN, D. A., WULF, G., EHRMANN, I.E., ELLIOTT, D.J., OKPANYI, V., ZECHNER, U., HAAF, T., MEINHARDT, A. and ENGEL, W. (2006). In vitro-differentiated embryonic stem cells give rise to male gametes that can generate offspring mice. Dev Cel/11: 125-132.

NICHOLAS, C.R., CHAVEZ, S.L., BAKER, V.L. and REIJO PERA, R.A. (2009) Instructing an embryonic stem cell-derived oocyte fate: lessons from endogenous oogenesis. Endocr Rev 30:264-283.
NOVAK, I., WANG, L., ERIKSSON, A., MAHDY, E. and HÖÖG, C. (2006). Mouse embryonic stem cells form follicle-like ovarian structures but do not progress through meiosis. Stem Cells 24: 1931-1936.

OHINATA, Y., OHTA, H., SHIGETA, M., YAMANAKA, K., WAKAYAMA, T. and SAITOU, M. (2009). A signaling principle for the specification of the germ cell lineage in mice. Cel/ 137: 571-584.

PELLEGRINI, M., FILIPPONI, D., GORI, M., BARRIOS, F., LOLICATO, F., GRIMALDI, P., ROSSI, P., JANNINI, E.A., GEREMIA, R. and DOLCI, S. (2008) ATRA and $K L$ promote differentiation toward the meiotic program of male germ cells. Cell Cycle 7: 3878-3888.

QING, T., SHI, Y., QING, H., YE, X., WEI, W., LIU, H., DING, M. and DENG, H. (2007). Induction of oocyte-like cells from mouse embryonic stem cells by cocultured with ovarian granulose cells. Differentiation 75: 902-911.

QING, T., LIU, H., WEI, W., YE, X., SHEN, W., ZHANG, D., SONG, Z., YANG, W., DING, M., and DENG, H. (2007). Mature oocytes derived from purifiued mouse fetal germ cells. Human Repor 23: 54-61.

SALVADOR, L. M., SILVA, C.P., KOSTETSKII, I., RADICE, G.L. and STRAUSS, J.F. (2008). The Promoter of the Oocyte-Specific Gene, Gdf9, is Active in a Population of Cultured Mouse Embryonic Stem Cells with an Oocyte-Like Phenotype. Methods 45: 172-181.

SZABO, P.E. and MANN, J.R. (1995). Biallelic expression of imprinted genes in the mouse germ line: implications for erasure, establishment, and mechanisms of genomic imprinting. Genes Dev 9: 1857-1868.

SZABO, P.E., HUBNER, K., SCHOLER, H. and MANN, J.R. (2002). Allele-specific expression of imprinted genes in mouse migratory primordial germ cells. Mech Dev115: 157-160.

TANAKA, S.S., TOYOOKA, Y., AKASU, R., KATOH-FUKUI, Y., NAKAHARA, Y., SUZUKI, R., YOKOYAMA, M. and NOCE, T. (2000) The mouse homolog of Drosophilavasa is required for the development of male germ cells. Genes Dev 14: 841-853.

TILGNER K., ATKINSON S.P., GOLEBIEWSKA A., STOJKOVIC, M., LAKO, M., ARMSTRONG, L. (2008). Isolation of Primordial Germ Cells from Differentiating Human Embryonic Stem Cells. Stem Cells 26: 3075-3085.

TOYOOKA, Y, TSUNEKAWA, N., AKASU, R. and NOCE, T. (2003). Embryonic stem cells can form germ cells in vitro. Proc Nat/ Acad Sci USA 100: 11457-11462.

TRAUTMANN, E., GUERQUIN, M.J., DUQUENNE, C., LAHAYE, J.B., HABERT, R and LIVERA, G. (2008). Retinoic acid prevents germ cell mitotic arrest in mouse fetal testes. Cell Cycle 7:656-664.

WANG, N. And TILLY, J.L. (2010). Epigenetic status determines germ cell meiotic commitment in embryonic and postnatal mammalian gonads. Cel/Cycle9: 1-11.

WEI, W., QUING, T., YE, X., LIU, H., ZHANG, D. YANG, W. and DENG, H. (2008). Primordial Germ Cell Specification from Embryonic Stem Cells. PLoS One 3 : 4013

WEST, F.D., MACHAACEK, D.W., BOYD, N.L., PANDYIAN, K., ROBBINS, K.R., STICE S.L. (2008). Enrichment and differentiation of human germ-like cells mediated by feeder cells and basic fibroblast growth factor signaling. Stem Cells 26: 2768-2776

WEST, J.H., VISWANATHAN, S.R., YABUCHI, A., CUNNIFF, K., TAKEUCHI, A., PARK, I., SERO, J.E., ZHU, H., PEREZ-ATAYDE, A., FRAZIER, A.L., SURANI, M.A. and DALEY, G. Q. (2009). A role for Lin28 in primordial germ-cell development and germ-cell malignancy. Nature 460: 909-914.

WEST, F.D., ROCHE-RIOS, M.I., ABRAHAM, S., RAO, R.R., NATRAJAN, M.S. BACANAMWO, M. and STICE, S.L. (2010). KIT ligand and bone morphogenetic protein signaling enhances human embryonic stem cell to germ-like cell differentiation. Hum Repr 25: 168-178.

WESTERN P. (2009). Foetal germ cells: striking the balance between pluripotency and differentiation. Int J Dev Bio/53: 393-409.

YU, Z., JI, P., CAO, J., ZHU, S., LI, Y., ZHENG, L., CHEN X. and FENG, L, (2009). Dazl Promotes Germ Cell Differentiation from Embryonic Stem Cells. JMo/ Cell Biol 1: 93-103. 


\section{Further Related Reading, published previously in the Int. J. Dev. Biol.}

\section{Interleukin-2 induces the proliferation of mouse primordial germ cells in vitro}

Cristina Eguizabal, Maria D. Boyano, Alejandro Díez-Torre, Ricardo Andrade, Noelia Andollo, Massimo De Felici and Juan Aréchaga Int. J. Dev. Biol. (2007) 51: 731-738

\section{Primordial germ cell migration}

Kathleen Molyneaux and Christopher Wylie

Int. J. Dev. Biol. (2004) 48: 537-543

\section{Myogenic potential of mouse primordial germ cells}

Francesca-Gioia Klinger, Maria-Lucia Scaldaferri, Anna Di Carlo, Marta Baiocchi, Marcello Coletta, Giulio Cossu and Massimo De Felici Int. J. Dev. Biol. (2003) 47: 303-305

Differentiation of mouse primordial germ cells into female or male germ cells

N Nakatsuji and S Chuma

Int. J. Dev. Biol. (2001) 45: 541-548

Primordial germ cell biology at the beginning of the new century (A tribute to Anne McLaren) (2009).

De Felici M.

Int. J. Dev. Biol. (2009) 53: 891-894

5 yr ISI Impact Factor $(2009)=3.253$

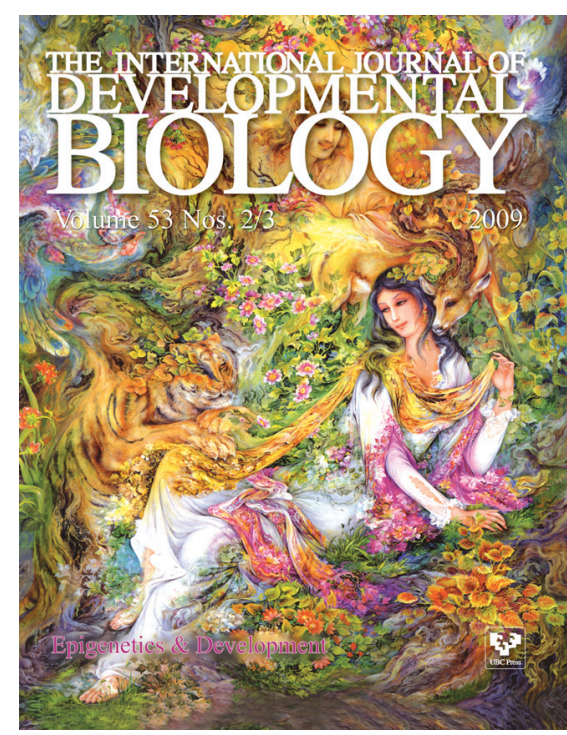

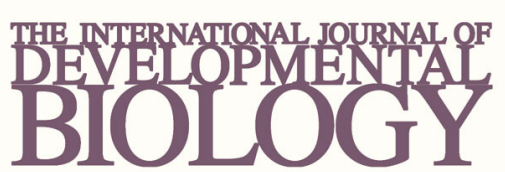

Volume 54 Nos. 6/7
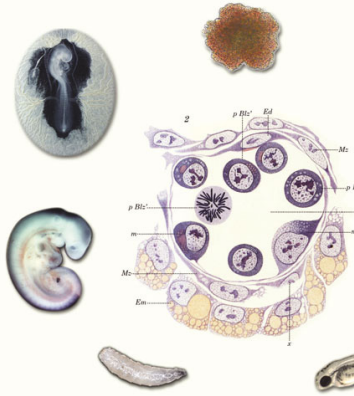

Developmental Hematopoiesis
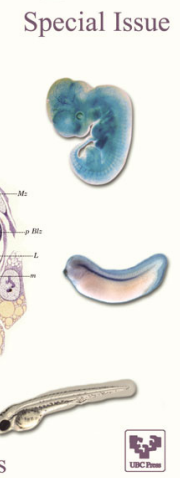

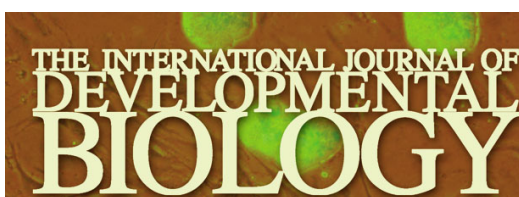

Volume 54 Nos. 11/12
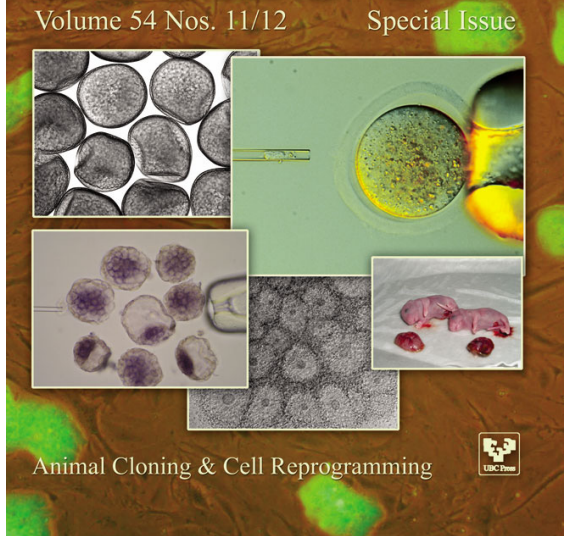